\title{
Longer Term Effects of Head Start
}

\author{
Eliana Garces \\ UCLA
}

Duncan Thomas

RAND and UCLA

Janet Currie

UCLA and NBER

December, 2000

Currie and Thomas thank the National Science Foundation (SBR-9512670) and National Institute for Child Health and Human Development (R01-HD3101A2) for financial support. The authors are solely responsible for the contents of the paper. We are grateful to Greg Duncan, Sandra Hofferth, and the Advisory Board of the Panel Survey of Income Dynamics for including the questions used in this study. 


\begin{abstract}
Little is known about the long-term effects of participation in Head Start. This paper draws on unique non-experimental data from the Panel Study of Income Dynamics to provide new evidence on the effects of participation in Head Start on schooling attainment, earnings, and criminal behavior. Among whites, participation in Head Start is associated with a significantly increased probability of completing high school and attending college, and we find some evidence of elevated earnings in one's early twenties. African Americans who participated in Head Start are significantly less likely to have been charged or convicted of a crime. The evidence also suggests that there are positive spillovers from older children who attended Head Start to their younger siblings.
\end{abstract}

Eliana Garces

Dept. of Economics

UCLA

Box 951477

LA, CA 90095-1477

egarces@ucla.edu
Duncan Thomas

Dept. of Economics

RAND and UCLA

Box 951477

LA, CA 90095-1477

dt@ucla.edu
Janet Currie

Dept. of Economics

UCLA and NBER

Box 951477

LA, CA 90095-1477

currie@simba.sscnet.ucla.edu 
Head Start, a public preschool program for disadvantaged children, is designed to close the gaps between these children and their more advantaged peers. Begun in 1965 as part of the "War on Poverty", Head Start enjoys widespread bi-partisan support. However, critics point out that there is little evidence regarding lasting benefits of participation in the program.

This paper provides evidence on the longer-term effects of Head Start using non-experimental data drawn from the Panel Survey of Income Dynamics (PSID). There are three features of the data that are key for this study. First, in 1995, special questions about participation in Head Start and other preschools were added to the interviews. These questions make it possible to ask whether Head Start confers any longer term benefits since they were asked of adult respondents age 30 and below who were eligible to participate in Head Start during the late sixties and seventies. Second, because the PSID is a panel which stretches back over a quarter century, we are able to control for family background and the environment in which each respondent grew up in great detail. Third, it is possible to evaluate the longer-term effects of Head Start programs that were actually in existence at the time the respondents were young children. This is important since most of the evidence cited in support of early intervention comes from model programs such as Perry Preschool which were funded at much higher levels than Head Start. Moreover, in contrast with the PSID which is a large, nationally representative data set, experimental evaluations tend to focus on relatively small, homogeneous populations. For both of these reasons, critics have questioned the generalizability of model evaluations.

Four indicators of economic and social success in adulthood are examined. We find that, for whites, participation in Head Start is associated with a significantly increased probability of completing high school and attending college as well as elevated earnings in one's early twenties. African Americans who participated in Head Start are significantly less likely to have been charged or convicted of a crime. We also find suggestive evidence that African-American males who attended Head Start are more likely than their siblings to have completed high school. Finally, we uncover some evidence of positive spillovers from older children who attended Head Start to their younger siblings, particularly with regard to criminal behavior. 
The rest of the paper is laid out as follows. First, we provide some background regarding the Head Start program and previous research. Second, the PSID data are described. Our statistical methods are then described and results follow in the fourth section. We end with conclusions.

\section{Background}

Head Start began as a summer program in 1965 with 561,000 predominantly African American children. It expanded to serve almost three-quarters of a million African American and white children in the summer of 1966 at which time about $\$ 1,000$ (in 1999 prices) was spent on each child. By the early 1970s, Head Start had become an all-year program that served considerably fewer children at a higher annual cost per child. For example, in 1971, the program served slightly less than 400,000 children at an annual cost of about $\$ 4,000$ per child. All three and four year old children living in poor families are eligible to enroll in the program and, today, it serves more than 800,000 children at a cost of around $\$ 5,400$ per child. (U.S. Administration on Children, Youth, and Families, 1999). While large, the program serves only about one-third of eligible children. This reflects the fact that the program, which is funded by appropriation, has never been fully funded. The program is administered at a local level -- there are over 1,400 local programs -- and is subject to federal guidelines. The guidelines specify that, in addition to providing a nurturing learning environment, Head Start should provide a wide range of services. These include, for example, facilitating and monitoring utilization of preventive medical care by participants, as well as providing nutritious meals and snacks.

Studies have shown that participation in Head Start is associated with short-term benefits, as indicated by improved test scores (see Barnett, 1995 and Karoly et al. 1998 for reviews of this literature). Many of these studies, however, have been criticized because they use ad hoc control groups, are subject to substantial attrition, or because sample sizes are small resulting in statistical tests that have limited power. Perhaps more troubling for the proponents of Head Start, is that evidence suggests positive effects on test scores tend to "fade out" by around the third grade so that Head Start children are no better off than controls at that point. Dissipation of test score gains does not necessarily imply that Head Start children do not benefit from starting school "on the right foot". 
For example, avoidance of grade repetition and special education may be associated with higher eventual schooling attainment. Head Start may also be associated with lasting improvements in noncognitive skills that are important for future success in life (c.f. Heckman et al., 2000).

Most of the evidence on longer-term benefits of early intervention is drawn from the Carolina Abcedarian Project and the Perry Preschool Project. The Carolina Abecedarian Project involved a 4 way design. At birth children were randomized into a treatment group that received enriched center-based child care services for 8 hours per day, 5 days a week, 50 weeks per year, from birth to age 5, and a control group that did not receive these services. At school entry, the children were again randomized into a "no further intervention" group and a group that received a "Home School Resource Teacher" who provided additional services (Campbell and Ramey, 1994, 1995). The investigators have now completed a follow-up assessment of the Abcedarian children at age $21 .{ }^{1}$ One hundred and four of the original 111 infants were assessed. At age 21, the children who received the preschool treatment had higher average tests scores and were twice as likely to still be in school or to have ever attended a four-year college.

The Perry Preschool intervention, which lasted 2 years, involved a half-day preschool every weekday and a weekly 90 minute home visit for 8 months of each year. Teacher/student ratios were 1 to 6, and all teachers had masters degrees and training in child development (Schweinhart et al., 1993). The intervention had positive effects on achievement test scores, grades, graduation from high school and earnings, as well as negative effects on crime rates and welfare use (as of age 27).

Both of these programs were funded at higher levels, and involved more intensive intervention by more highly trained staff than a typical Head Start program. For example, in 1998 it cost $\$ 5,021$ to keep a child in a part-day Head Start program for 34 weeks a year. The two-year, part-day Perry Preschool intervention cost \$12,884 per child (in 1999 dollars) (Karoly, et al. 1998). ${ }^{2}$

\footnotetext{
${ }^{1}$ The following discussion is taken from the Executive Summary of the Carolina Abcedarian Project at www.fpg.unc.edu/verity.

${ }^{2}$ Twenty percent of the children participated in the program for only one year. The cost figure given by Karoly et al. is a weighted average that takes this into account. These figures imply that the cost per year was about 7,000 1999 dollars.
} 
The preschool component of the Abcedarian intervention (which was full-day) cost about $\$ 15,000$ per child, per year, and this part of the intervention lasted 5 years. ${ }^{3}$ Thus, the results of these programs probably provide an upper limit on what one could reasonably expect from Head Start.

There have been few attempts to measure the long-term impacts of Head Start, or similar large-scale publicly funded programs. Reynolds (1998), Reynolds et al. (2000) and Temple et al. (1999) are important exceptions. They study the Chicago Child-Parent Centers (CPC), an intervention that began with an enriched preschool program, and followed up with an enriched curriculum for school-aged children up to age 9. One way to think about this intervention is that it is similar to providing a Head Start-like preschool program and then improving the school subsequently attended by the Head Start children.

Reynolds (1998) followed a sample of children who had all participated in the preschool and kindergarten components of the CPC program through 7th grade. Some participated in CPC after kindergarten (the treatments) and some did not (the controls). In addition, some attended schools in which the extended program was offered for 2 years, while some attended schools in which it was offered for 3 years. This variation can also be used to identify program effects. Reynolds finds significant reductions in the rates of grade retention, special education, and delinquency in the treatment group, as well as higher reading scores, and his results are robust to the use of different methodologies. ${ }^{4}$

Temple et al. follow the CPC children to the end of high school and find that CPC reduced high school dropout by $24 \%$, and that the size of the effect grows with the time that children spent in the program. Reynolds et al. look at several additional outcomes including delinquency, crime,

\footnotetext{
${ }^{3}$ Ramey, Campbell and Blair (1998) state that on average the preschool component of the program cost about $\$ 6,000$ per year. Children entered the preschool component between 1972 and 1983. Six thousand 1978 dollars are worth approximately \$15,000 1999 dollars.

${ }^{4}$ Reynolds uses three different methods. First, he conducts an analysis of the initial differences in test scores between the two groups, and finds that most of it can be explained by observable characteristics. That is, there do not appear to be large pre-existing unobservable differences between the treatments and the controls. Second, he estimates a model in which selection into the treatment group is controlled for (via Heckman's (1979) procedure). In this model, it is assumed that the characteristics of each school site affected selection into the treatment group without having additional direct effects on child outcomes. A third approach is to compare children in schools which offered the treatment for two years to those in schools that offered it for three.
} 
and a skills test and find significant effects of CPC on all of the outcomes they examine. They include a simple cost-benefit analysis which suggests that a dollar spent on the program saved \$3.69 in future costs to government.

Currie and Thomas (1995) use non-experimental data drawn from the National Longitudinal Survey's Child-Mother files (NLS-CM) to evaluate Head Start. They attempt to control for unobserved characteristics of children by comparing siblings who participated in Head Start with those who did not. The idea is that by using siblings as the controls, any shared characteristics of family background will be controlled.

Since they draw on a large-scale survey that is nationally representative, the Currie and Thomas study is one of a handful that includes a substantial number of Head Start children who are not African-American. This is important since, although African Americans participate at higher rates than whites, the majority of Head Start children are not African American. Currie and Thomas report that for children of all racial and ethnic backgrounds, there are substantial and significant gains in test scores associated with attending Head Start. For African-American Head Starters, these gains "fade out" while they are still in elementary grades. For whites, the gains persist into adolescence and participation in Head Start is also associated with reduced grade repetition. It is worth emphasizing that since the initial gains in test scores are the same for whites and African-Americans, the racial differences are likely to have less to do with the Head Start program and more to do with the child's experiences after finishing the program. ${ }^{5}$

In sum, there do appear to be short term positive effects of participation in Head Start on outcomes such as grade repetition. That fact, in combination with evidence regarding positive longerterm effects of model early interventions make it reasonable to suppose that there may be lasting benefits associated with participation in Head Start programs. Whether there are, however, remains an open question and is the subject of this paper.

\footnotetext{
${ }^{5}$ Currie and Thomas (2000) find that African American children who attended Head Start go on to attend schools of lower quality than other African American children. However, the same is not true among whites. Thus, poor school quality offers a potential explanation for fade out of Head Start effects among African American children. The CPC results discussed above also suggest that improved school quality can prevent fade out.
} 


\section{Data}

The PSID began in 1968 with a survey of 4,802 households composed of 18,000 individuals. These households, and new households formed by the original head, spouse and their children have been followed ever since. In 1995, special questions on early childhood education experiences were included in the interview on a one-time basis. Adult respondents age 30 or below were asked whether they had ever been enrolled in Head Start and whether they had attended any other preschool or daycare program. Since our interest is in the longer-term effects of participation in Head Start, we focus on slightly less than 4,000 adults (age 18 and older in 1995) who answered these questions.

These responses provide a unique opportunity to assess the longer-term effects of Head Start using non-experimental data. We view this evidence as an important complement to experimental evaluations for several reasons. Since experimental study populations tend to be small and homogenous, the results of those evaluations may not be generalizable to the broader population. In contrast, the sample we analyze is representative of cohorts born in the United States between 1964 and 1977 and spans the full spectrum of socio-economic diversity of those birth cohorts. In addition, experimental evaluations of early childhood enrichment programs have generally involved far more intensive interventions than a typical Head Start child would experience; PSID respondents, in contrast, participated in the programs as they existed in the United States when the respondents were children.

These benefits of the PSID come at a price. First, because we are using non-experimental data, we need to address the fact that children are not randomly assigned to Head Start. Second, because we are measuring the longer-term effects of Head Start participation, and that information was not collected prospectively, the questions on early childhood education are asked retrospectively and may be contaminated by recall error. We have conducted several experiments to evaluate the quality of the data and we describe these experiments before discussing the issue of non-random assignment. Sample summary statistics are reported in Table 1. 
Overall, $10 \%$ of the 1964-1977 birth cohort sample in the PSID report having attended Head Start and $22 \%$ report having attended some other type of preschool program. ${ }^{6}$ If we take the same birth cohorts and assume that the average child who participated was in the program for one year, then the numbers of participants reported by the Head Start Bureau for each year imply a national participation rate of slightly over $12 \% .^{7}$ National participation rates were high for those born in $1964 / 65$ (17\%), fell to $13 \%$ for the 1966 cohort, to $11 \%$ for the 1967 cohort, and then declined slowly to $10 \%$ for the 1970 birth cohort. Enrolment rates subsequently rose for those born during the decade of the 1970s to slightly over 12\% (among the 1977 birth cohort). This pattern is replicated remarkably closely in the PSID sample with one important exception. Among the earliest two birth cohorts in our sample (1964/5), reported participation rates are much lower than the national rates (6\% in the PSID). Participation in the 1966 cohort is higher but still below the national rate (8\% in PSID). The PSID and national rates are very close in the 1967 birth cohort (11\%) and for all other birth cohorts, the PSID mimics the national numbers. (Reported participation in the PSID declines to $9 \%$ in the early 1970 s and then rises to $12 \%$ by the 1977 birth cohort, the last cohort in our sample).

Recall that for the oldest birth cohorts, Head Start was primarily a summer program. It is not surprising that the reported rate of participation in Head Start among these birth cohorts in the PSID is much lower than the national rate. First, there is abundant evidence in the survey research literature that the more salient a life event, the more likely it is to be recalled; ${ }^{8}$ participation in a

\footnotetext{
${ }^{6}$ These enrollment rates are weighted so that the PSID sample is representative of the population. We have raked the 1995 PSID sample of respondents born between 1965 and 1977 to the 1995 Current Population Survey matching on the joint distribution of race, sex and year of birth. We prefer these weights to the PSID longitudinal weights for two reasons. First, the PSID longitudinal weights are raked to the 1967 United States population (and then take into account attrition) and so are not representative of the population in 1995 (since the structure of the population has changed during the quarter century). Second, all new entrants into the PSID sample are assigned a zero PSID longitudinal weight; many of the respondents in our sample are new entrants to PSID and so would contribute no information.
}

${ }^{7}$ This estimate is based on data reported by the Head Start Bureau on enrollments in each year of the program and the number of births, reported by the National Center for Health Statistics. (Head Start Bureau, 1999; National Center for Health Statistics, 2000.)

${ }^{8}$ See Sudman, Bradburn and Schwarz (1996) 
summer Head Start program is not likely to be as salient to a respondent as full-year participation in one's first school-oriented program. Second, many of the children who participated in Head Start during the summer are likely to have attended some other preschool during the rest of the year and PSID respondents are more likely to have reported their preschool experience during the school year rather than in the summer. By the early 1970s, Head Start had become a full-year program. Respondents born in the late 1960s would have participated in this full-year program rather than the summer one. Since the summer program is substantially different from the full-year program we have excluded the oldest birth cohorts from the analyses presented below. ${ }^{9}$ Among those respondents born between 1966 and 1977, the national enrollment rate according to the Head Start Bureau is 11.1\%; of the PSID respondents, $10.7 \%$ (standard error=0.6\%) report having attended Head Start.

The racial composition of Head Start children is not reported for every year by the Head Start Bureau. Taking 1980 as an example, 42\% of Head Start participants were African American. Since about $14 \%$ of the nation's children were African American, this implies that about $33 \%$ of those children participated in Head Start and that the enrollment rate was around 7\% among white children. The implied enrolment rates in the PSID are very close: for the 1975 birth cohort, $36 \%$ of African Americans and 5\% of whites report participation in Head Start.

Seminal work by Ebbinghaus (1894) and many subsequent studies in the survey research literature have shown that recall error tends to increase as a respondent is asked to stretch further back in time. This literature also demonstrates that the rate of forgetting tends to be slower as the salience of recalled events increases. If recall error seriously contaminates responses in the PSID, then we would expect the gap between the national enrollment rates and those reported in the PSID to be greater among the earlier birth cohorts. As indicated in the discussion above, excluding the 1964/65 birth cohort because they participated in a summer program, enrollment rates implied by the

\footnotetext{
${ }^{9}$ The 1964 and 1965 birth cohorts have been excluded. Some of the 1966 cohort will have participated in the full year program and some in the summer program. Assuming that full year participation is more salient, it is likely that those respondents in this birth cohort who report participation in Head Start were full year participants. (One in ten participants report participation in another preschool which is slightly lower than the rate for later birth cohorts.) We have experimented with dropping the 1966 birth cohort from our analytical sample. The regression results discussed below are little impacted by this restriction and none of the significant or important results is affected.
} 
PSID are not only very close to the national rates but the PSID rates mimic the temporal pattern of the national rates. We find no pattern of differences by birth year of the respondent: in a regression of enrollment rates on year of birth (specified as a spline with a knot at 1970 birth year), there are no substantial or significant differences between the national rates and those implied by the PSID.

Our third assessment of the quality of the recall data on Head Start participation exploits the fact that because the PSID is a long-term panel, we know family income when the respondent was a child. We have calculated average per capita family income (in 1999 prices) at the time the respondent was age 3, 4, 5 and 6, and, as shown in Table 1, Head Start children tend to be drawn from families whose incomes were much lower when the respondent was a young child. Figure 1 presents the fraction of respondents who report attending Head Start and other preschools by per capita family income. Of respondents whose families were in the bottom quartile of the income distribution, about 30\% report attending Head Start. The fraction declines with income and is close to zero for all respondents whose families were above median income. ${ }^{10}$ The fraction of respondents who attended other preschools rises monotonically with income. The shapes of the relationships between income and participation in Head Start and other preschool programs are remarkably similar to those reported in Currie and Thomas (1995), which are based on prospective reports in the NLSYCM. Respondents who report participation in Head Start as children were clearly disadvantaged when young, relative to other respondents. They are more likely to have been living with a single mother at that time, their mothers are less well-educated and they are more likely to have been low weight at birth. (See Table 1.)

We noted above that African Americans are more likely to participate in Head Start than whites. In part, this is because African Americans are more likely to be poor. However, even if income is controlled, African Americans are still more likely to attend Head Start than whites -- a pattern that is also reported by Currie and Thomas. However, mothers of white Head Start children

\footnotetext{
${ }^{10}$ Given that Head Start has long enjoyed widespread public support, it is possible that some people who attended other types of preschools erroneously label them "Head Start". If reported Head Start children had family incomes greater than $150 \%$ of the poverty line in every preschool year, and never received any form of welfare then we reclassified them as "other preschool". About 5\% of the reported Head Start participants in each year fell into this category.
} 
tend to be less educated than those of African American Head Start children, although they are less likely to be single. White Head Start children in the PSID are almost twice as likely to have been low birthweight than African American Head Start children (14\% and 8\%, respectively) although in the general population, African American children are substantially more likely to suffer from low birthweight than whites. These differences suggest that the mechanisms underlying participation in Head Start are different for African Americans and whites, and suggest that it may be fruitful to examine the two groups separately.

In sum, among the 1966-1977 birth cohorts in the PSID, retrospectively reported rates of participation in Head Start match the national enrollment rates very closely; Head Start participants were clearly disadvantaged around the time of preschool; and the link between participation and family income mimics the associations observed in other data sources. On balance, recall data on Head Start participation seem to be of high quality. While there is likely to be some classification error by respondents, we find no evidence of systematic reporting bias. Random classification error will tend to obscure positive benefits of Head Start, and since there is no a priori reason for a positive bias because of recall error, our estimates are likely to provide a lower bound.

\section{Empirical methods}

The aim of this study is to ask whether participation in Head Start results in greater economic or social success later in life. We focus on four outcomes measured in adulthood: completion of high school, attendance at some college, $\ln$ (earnings) if the respondent worked, and whether the respondent ever reported being charged or convicted of a crime.

A natural starting point would be to estimate a model in which each outcome of an individual respondent, $\mathrm{Y}_{\mathrm{i}}$, is assumed to depend on participation in Head Start, HDST, some other preschool, OPRE, and a set of individual-specific controls, $\mathrm{X}$ :

$$
\mathrm{Y}_{\mathrm{i}}=\alpha_{0}+\alpha_{1} \mathrm{HDST}_{\mathrm{i}}+\alpha_{2} \mathrm{OPRE}_{\mathrm{i}}+\alpha_{3} \mathrm{X}_{\mathrm{i}}+\varepsilon_{\mathrm{i}}
$$

where HDST and OPRE are indicator variables and $\varepsilon$ captures unobserved heterogeneity. The vector $\mathrm{X}$ includes observable exogenous variables that are likely to be correlated with outcomes such as the respondent's year of birth, and indicators equal to one if the respondent is female or African American. It is important to include a control for whether the respondent attended a preschool other 
than Head Start for two reasons. First, we do not want to erroneously attribute the effects of other preschools to Head Start. Second, it is useful to compare the effects of Head Start to those of other preschools, as is discussed further below.

As noted above, the key problem with interpretation of [1] is that participation in Head Start (or other preschools) is not randomly assigned and so these covariates may be correlated with the unobservables, $\varepsilon$. In that case, estimates of the effect of Head Start will be biased. For example, Head Start is targeted towards disadvantaged children. Children from poor families and low income neighborhoods are more likely to participate in the program (as shown in Table 1). Moreover, children who are perceived to be "at risk" because of learning disabilities, or a negative home environment are often referred to Head Start by social agencies. Failure to control for these intervening characteristics will result in their being included in $\varepsilon_{\mathrm{i}}$.

To the extent that these characteristics are correlated with HDST, estimates of $\alpha_{1}$, the long run "effect" of Head Start, will be biased. Because disadvantaged children are more likely to participate in Head Start, $\alpha_{1}$ will probably be biased downwards. Children who attend other preschools are likely to come from more advantaged backgrounds and so $\alpha_{2}$ is likely to be biased upwards. One approach to addressing this concern is to include measures of the relevant intervening characteristics in the vector $\mathrm{X}$.

The PSID is a good data source for taking this approach since extensive information on the child's family background has been collected on an annual basis since 1968 . Hence, we augment the vector $\mathrm{X}$ by including: maternal and paternal education of the respondent; a spline in family income when the child was of preschool age; family size measured at age 4; whether the respondent lived with both parents at age 4; an indicator for whether the respondent was the oldest child and birthweight. ${ }^{11}$ We have also experimented with adding controls for whether the mother worked or

\footnotetext{
${ }^{11}$ Missing values were handled by first determining whether a value could be assigned using information from other waves of the PSID. For example, in some cases, father's education could be assigned to one sibling by looking at reported values for the other sibling. Using the average of household income available at age 4, 5, and 6 resulted in few instances of missing data for this variable (less than $1 \%$ of the sample). This average income measure is what we loosely refer to as income at preschool age. When data remained missing, we assigned the mean value from the sample and included a dummy variable in the regression which indicated that a value had been assigned.
} 
was on welfare when the child was age 4. (The addition of these variables had little impact on the results reported below.)

Despite the richness of the PSID, there may well be other unmeasured characteristics that distinguish Head Start children from their peers and which cannot be controlled in the regression model. If, conditional on the controls, these other characteristics are correlated with observable differences between Head Starters and other children then the estimated effects of Head Start will be biased. For example, if parents who send their children to Head Start (or other preschools) place a higher value on building human capital at an early age, than other parents, and if that human capital accumulation is associated with better outcomes later in life, then this unobserved difference will result in an upward bias in the Head Start "effect", $\alpha_{1}$. In this case, it will be the (unobserved) parental emphasis on education that leads to better outcomes in adulthood rather than Head Start (or other preschool) attendance per se.

To the extent that parental taste for human capital accumulation does not differ between siblings, then it can be absorbed in a family-specific fixed effect, $\mu_{\mathrm{f}}$ :

$$
\mathrm{Y}_{\mathrm{if}}=\beta_{0}+\beta_{1} \operatorname{HDST}_{\mathrm{if}}+\beta_{2} \mathrm{OPRE}_{\mathrm{if}}+\beta_{3} \mathrm{X}_{\mathrm{if}}+\mu_{\mathrm{f}}+\xi_{\mathrm{i}}
$$

This design controls for any unobserved family characteristics that have the same linear and additive effect on the adult outcomes of all siblings. As a practical matter, $\mu_{\mathrm{f}}$ is specified as a mother-specific fixed effect in the empirical models below.

The fixed effects method is not without its own limitations. First, the effective sample includes only those respondents with at least one sibling in the sample (which is slightly over half of the total sample). In these models, the effect of Head Start, $\beta_{1}$, is identified by comparing the outcomes of adults who participated in Head Start as children with the outcomes of the siblings who $\operatorname{did}$ not (255 respondents from 100 families). ${ }^{12}$

Second, the effects of random measurement errors may be exacerbated in a fixed effects framework. That is, by focussing on differences between siblings within a family, we may difference

\footnotetext{
${ }^{12}$ Although this sample is small, it is larger than many of the experimental samples discussed in Barnett's (1995) summary of the literature. It is worth noting as well that given the low Head Start participation rates among whites, there are more African-American than white families with differences in the Head Start participation of siblings.
} 
out much of the true signal in the data, and result in an under-estimate of the positive effects of Head Start. On the other hand, fixed effects can mitigate the effects of some forms of non-random measurement error. Suppose for example, that all siblings in a family erroneously report that they did not attend Head Start but some other form of preschool. This will have no impact on the estimated effect of Head Start in the fixed effects framework.

The third problem arises when $\mu_{\mathrm{f}}$ is not fixed within a family. This would arise if parents treat siblings differently. Say, for example, parents invest more in the human capital of one sibling; if they also send that child to Head Start, $\beta_{1}$ will be biased upwards. It is more likely, however, that parents who want to invest in the human capital of a child send that child to another preschool since Head Start is targeted at disadvantaged children. So it is, in fact, $\beta_{2}$ that is more likely to be biased upwards. In this case, the difference $\beta_{1}-\beta_{2}$ could be considered a lower bound estimate of the effect of Head Start where the estimate takes into account systematic differences in the treatment of siblings which result in one of them attending Head Start or another preschool while the other does not. Hence, we report this difference in Table 2 below.

Another reason $\mu_{\mathrm{f}}$ may not be fixed within a family is that siblings experience different environments while growing up. For example, one child may participate in Head Start because family resources are low when the child is age 4 or 5 but siblings may attend other preschools (or no preschool) because resources are less constrained when the siblings are age 4 or 5 . For this reason, we include a control for family income averaged over the period that the respondent was age 3,4 , 5 and 6 in all our regression models.

A special case in which the family effect is not fixed arises when benefits associated with Head Start spillover from one sibling to the other. The Head Start program emphasizes parent participation and teaches parenting skills which might affect all children. Moreover, it is possible that what one child learns may "spillover" to siblings. In general, in the fixed effects framework, spillovers will tend to result in downward biased estimates of the effect of Head Start because they reduce the differences in outcomes between siblings who did and did not attend the program. We will explore evidence that spillovers are important below. 


\section{Results}

Table 2 presents our empirical results. For each of the four adult outcomes, we present a set of estimates following the empirical strategy outlined above. In each panel, we report the correlation of the outcome with participation in Head Start and with participation in other preschools as well as the difference between these correlations. Standard errors below the estimates take into account correlations within families (and are robust to arbitrary forms of heteroskedasticity). For simplicity of interpretation of the coefficients, we present results based on OLS; logit (and Chamberlain fixed effects logit) estimates provide substantively the same results.

We begin with the probability that a child completed high school. About three-quarters of the sample of respondents completed high school. The first column is based on OLS estimates of model [1]. In addition to HDST and OPRE, the model includes year of birth, gender of the respondent, and whether the respondent is African American. These OLS estimates indicate that respondents who reported attending Head Start were about 9\% less likely than stay-at-home children to complete high school, while those who attended other preschools were about $9 \%$ more likely to complete high school. ${ }^{13}$ In the second column, the sample is restricted to respondents with at least one sibling: the estimates are essentially the same as the full sample. The results demonstrate once again that adults who attended Head Start are significantly less likely than other children to have completed high school. This result probably reflects the fact that Head Start children are disadvantaged relative to other children, as shown in Table 1.

Column 3, which includes a series of controls for family background, demonstrates that this interpretation has merit. ${ }^{14}$ Controlling for these observable characteristics, high school graduation

\footnotetext{
${ }^{13} \mathrm{~A}$ small fraction (8\%) of respondents report attending both Head Start and also other preschools. For these respondents, both indicator variables are turned on. The Head Start effect is, therefore, the marginal effect of attending Head Start over and above the effect of participating in other preschools. We have experimented with including an additional indicator that isolate this group who attended both. The estimates suggest that the effects of other preschools are dominant: in all models that include family controls, there are no significant differences between other preschoolers and those who attended both Head Start and other preschools.

${ }^{14}$ In addition to those in columns 1 and 2, the controls are maternal education, paternal education, whether the mother was the head of the household, family income at age 4-6 (a spline in log income with knots at each quartile), family size at age 4, birth order, whether the respondent is the oldest child in the family, whether the respondent was a low birthweight baby.
} 
rates are the same independent of reported preschool experience. Estimates that include maternal fixed effects are reported in column 4. As discussed above, these estimates show the effects of controlling for both observed and unobserved characteristics of mothers that are fixed over time. These estimates are consistent with those shown in column 3 in that they suggest that the negative effects of Head Start shown in column 1 are an artifact of the disadvantages of Head Start children, rather than an effect of the program.

Columns 5 and 6 of Table 2 show estimates stratified by race. This experiment is of interest give the differential effect of Head Start by race reported in Currie and Thomas (1995). The estimates suggest that whites who attended Head Start are 20 percentage points more likely to complete high school than siblings who did not attend. However, there is no statistically significant effect for African Americans.

In the final two columns of the table, the sample is restricted to those respondents whose mother had no more than a high school education. We examine this sub-sample for two reasons. First, the probability that a respondent attended Head Start rises as socio-economic status declines and so the percentage of reported Head Starters who are false positives is likely to be lower in this group. Second, since Head Start is targeted towards the most disadvantaged, it is of interest to know whether any long-term benefits associated with the program accrue to those from the poorest backgrounds. (We have also stratified on family income at age 3-6; the results are substantively the same but estimated with less precision in a few cases; these results are not shown.) We find that the long term benefits of Head Start are even greater for whites in this group: those who attended Head Start are nearly $30 \%$ more likely to have completed high school than their siblings.

The second panel of Table 2 focusses on the next step in education: attendance at college. In the absence of controls for family background, those who attended Head Start are less likely to go to college relative to those who went to other preschools and, to a lesser extent, relative to those who attended no preschool. However, column 3 shows that after controlling observable differences in family background, Head Starters are more likely to attend college. Column 4 shows that this is also true when unobserved fixed differences between families are controlled using mother fixed effects (although significance is marginal because of the sample size). Columns 5 and 6 suggest that 
this effect is driven by white children who attended Head Start. These children are $28 \%$ more likely to attend college than siblings who attended no preschool and nearly $20 \%$ more likely than those who attended other preschools. ${ }^{15}$

Higher educational achievement is associated with many indicators of social and economic success in adulthood. In the third panel, we focus on one dimension of that success: annual earnings conditional on working. ${ }^{16}$ To smooth out year to year fluctuations (and fill in some missing values), we examine the logarithm of average earnings in each year the respondent reported working between the ages of 23 and 25. There is little evidence that Head Start is associated with earnings at this age except in the case of whites children of high school dropouts (see column 8). In this group, children who attended Head Start earn significantly more than their siblings who did not attend preschool and also more than those who attended other preschools (although this latter difference is not significant). It is reasonable to suppose that earnings benefits associated with Head Start may emerge more clearly as these people move through their working lives given the findings for schooling attainment above and the well-documented association between schooling and earnings. (We have also examined whether Head Start is associated with elevated rates of labor force participation among young adults but we find no statistically significant effects.)

The final panel examines the incidence of reported criminal activity. Each respondent is asked whether he or she has ever been charged or convicted of any criminal offence. Thus, this definition of criminal activity includes very serious crimes -- such as those that involve periods of incarceration -- as well as more minor offenses such as drunken driving. Slightly less than $15 \%$ of the sample respondents report some criminal activity. Column 1 suggests that people who attended Head Start are significantly more likely than those who attended other preschools to have had a brush with the law, although the point estimates for HDST and OPRE are not individually statistically significant. However, column 3 indicates that this gap disappears when observable characteristics are

\footnotetext{
15 This racial difference is also evident in OLS models that control for observable but not unobservable differences. The point estimate on Head Start is 0.141 for whites with a standard error of 0.073 , but the corresponding coefficient is not statistically significant for African Americans.

${ }^{16}$ Since not all young adults work, the sample available for these models is smaller. There are 1383 observations in total and 728 for people with siblings in the sample. Of these, 272 are black and 456 are white.
} 
controlled, and column 4 shows that when both observed and unobserved characteristics are controlled the gap becomes negative. That is, people who attended Head Start are significantly less likely to report criminal activity than siblings who attended another preschool.

In contrast to the results for educational attainment, this estimate appears to be driven by African Americans. Columns 5 and 6 show that African American children who attended Head Start are 12 percentage points less likely to report criminal activity than siblings who did not. The effect is slightly larger among African Americans whose mothers have only a high school education, as shown in column 7 .

We have also explored the question of whether the effects of Head Start differ with other demographic characteristics of the respondent, such as gender and birth order. While we find no significant differences in the effect of Head Start on males, relative to females, there is one instance in which large differences in the point estimates for males and females emerge. Relative to their siblings, males who attended Head Start are between 15 and 20 percentage points more likely to complete high school than female respondents. This is true for both whites and African Americans. The gap disappears when we examine college attendance and there are no gender differences with respect to earnings or criminal activity.

Turning to birth order, we asked whether there were any significant differences between first born children and others. Again, we found no statistically significant differences in the effects of Head Start between first born children and their siblings. However, once again, the point estimates are suggestive. Among African Americans, higher birth order children appear to benefit more from Head Start than their older siblings, particularly with regard to schooling outcomes.

As discussed above, larger effects for younger siblings could reflect the presence of spillovers of Head Start benefits from older to younger children. It is plausible to assume that spillovers flow in this direction rather than from younger to older siblings for two reasons. First, older siblings are more likely to teach (or be a role model) for younger siblings. Second, the Head Start program requires parent participation and some of the skills that parents learn are likely to benefit younger children more than older siblings. For example, if a parent of a 5 year old Head Starter and a 1 year old learns that it important to read to children from infancy, the 1 year old is likely to benefit more 
than the 5 year old from this new knowledge regardless of whether the 1 year old goes on to attend Head Start.

In order to ask whether these sorts of spillovers are important, we have estimated models which allow the effects of Head Start (and other preschools) to differ if an older sibling participated in the program. For the two schooling outcomes, the spillover effects of Head Start tend to be positive but they are relatively small and not significant. There is no evidence of spillover effects on earnings. There do, however, appear to be spillover effects for criminal activity: respondents with an older sibling who attended Head Start are considerably less likely to have been charged with a crime and this effect reinforces the benefits associated with the index respondent's participation in Head Start. For example, among African Americans whose mothers only have a high school education, the respondent is $11 \%$ less likely to have had a brush with the law if an older sibling attended Head Start (t statistic=2.0) and 27\% less likely if the respondent him or herself also attended Head Start (t statistic=3.2).

In sum, there is evidence that Head Start attendance is associated with significant improvements in educational outcomes and possibly with higher earnings among whites, while among African Americans, we find evidence that past Head Start attendance reduces reported criminal activity. We also find some suggestive evidence that Head Start participation improved rates of high school completion among African-American males (though these estimates were not statistically significant), and that there are spillover effects of Head Start attendance from older to younger siblings.

\section{Conclusions}

Very little is known about the long-term effects of participation in Head Start, although previous research showing "fadeout" in effects on test scores has caused some analysts to be pessimistic. This paper uses non-experimental data on young adults in the PSID to ask whether participation in Head Start is associated with benefits in adulthood. We exploit the panel dimension of the PSID and control for observable differences between respondents when they were young 
children. We also exploit the family-based sampling frame of the PSID by including maternal fixed effects and comparing adult outcomes of siblings.

Participation in Head Start has positive effects on the probability of attending college. However, these positive effects are driven by whites. Whites also see large increases in the probability of graduating from high school, and possibly in earnings as young adults. We did not find statistically significant effects for African-Americans, though we did find some suggestive evidence that Head Start may increase the probability of graduating from high school among African-American males. We also found that African-Americans who participated in Head Start were significantly less likely to have been charged or convicted of a crime than siblings who did not. Head Start did not appear to have any significant effect on reported criminal activity among whites. Finally, we find some evidence suggesting there are positive spillovers from older children who attended Head Start to their younger siblings, particularly with regard to criminal behavior.

We have sought to carefully describe the limitations as well as the strengths of our study sample and methods. With those limitations in mind, we conclude that the results are supportive of the view that Head Start participants gain social and economic benefits that persist into adulthood. Moreover, as we have argued above, our methods are likely to provide lower bound estimates on the positive effects of Head Start. However, it would be foolhardy to leap to conclusions about the longterm efficacy of a large program like Head Start on the basis of a single study. Much remains to be discovered about the nature and distribution of longer-term benefits from early childhood interventions. 


\section{References}

Barnett, Steven. 1995. "Long-Term Effects of Early Childhood Programs on Cognitive and School Outcomes" The Future of Children. 5:3, 25-50.

Campbell, Frances A. and Craig T. Ramey. 1994. "Effects of Early Intervention on Intellectual and Academic Achievement: A Follow-up Study of Children from Low-Income Families" Child Development. 65, 684-698.

Campbell, Frances A. and Craig T. Ramey. 1995. "Cognitive and School Outcomes for High-Risk African-American Students at Middle Adolescence: Positive Effects of Early Intervention" American Educational Research Journal. 32:4, 743-772.

Currie, Janet and Duncan Thomas. 1995. "Does Head Start Make a Difference?" American Economic Review. 85:3, 341-364.

Currie, Janet and Duncan Thomas. 1999. "Does Head Start Help Hispanic Children?" Journal of Public Economics.

Ebbinghaus, Hermann. 1894. Memory: A contribution to experimental psychology, New York: Dover.

Heckman, James J., JingJing Hsse and Yona Rubinstein. 2000. "The GED is a Mixed Signal: The Effect of Cognitive and Non-Cognitive Skills on Human Capital and Labor Market Outcomes", University of Chicago xerox.

Karoly, Lynn et al. 1998. Investing in our Children: What we Know and Don't Know About the Costs and Benefits of Early Childhood Interventions. Santa Monica: RAND.

Ramey, Craig, Francis Campbell and Clancy Blair. "Enhancing the Life Course for High-Risk Children" in Jonathon Crane (ed) Social Programs that Work (New York: Russell Sage), 1998, 184-199.

Reynolds, Arthur. 1998. "Extended Early Childhood Intervention and School Achievement: Age Thirteen Findings from the Chicago Longitudinal Study" Child Development. 69:1, 231-246.

Reynolds, Arthur et al. 2000. "Long Term Benefits of Participation in the Title 1 Chicago ChildParent Centers", xerox, University of Wisconsin, Madison.

Schweinhart, Lawrence J., Helen Barnes, and David Weikart. 1993. Significant Benefits: The High/Scope Perry Preschool Study Through Age 27. Monograph of the High/Scope Educational Research Foundation, Number Ten, Ypsilanti, Michigan: High-Scope Educational Research Foundation.

Sudman, Seymour, Norman M. Bradburn and Norbert Schwarz. 1996. Thinking About Answers: The Application of Cognitive Processes to Survey Methodology, San Francisco: Jossey-Bass Press. 
Temple, Judy, Arthur Reynolds, and Wendy Miedel. 2000. "Can Early Intervention Prevent High School Dropout?" Urban Affairs 35:1, March, 31-56. 
Figure 1: Reported participation rates in

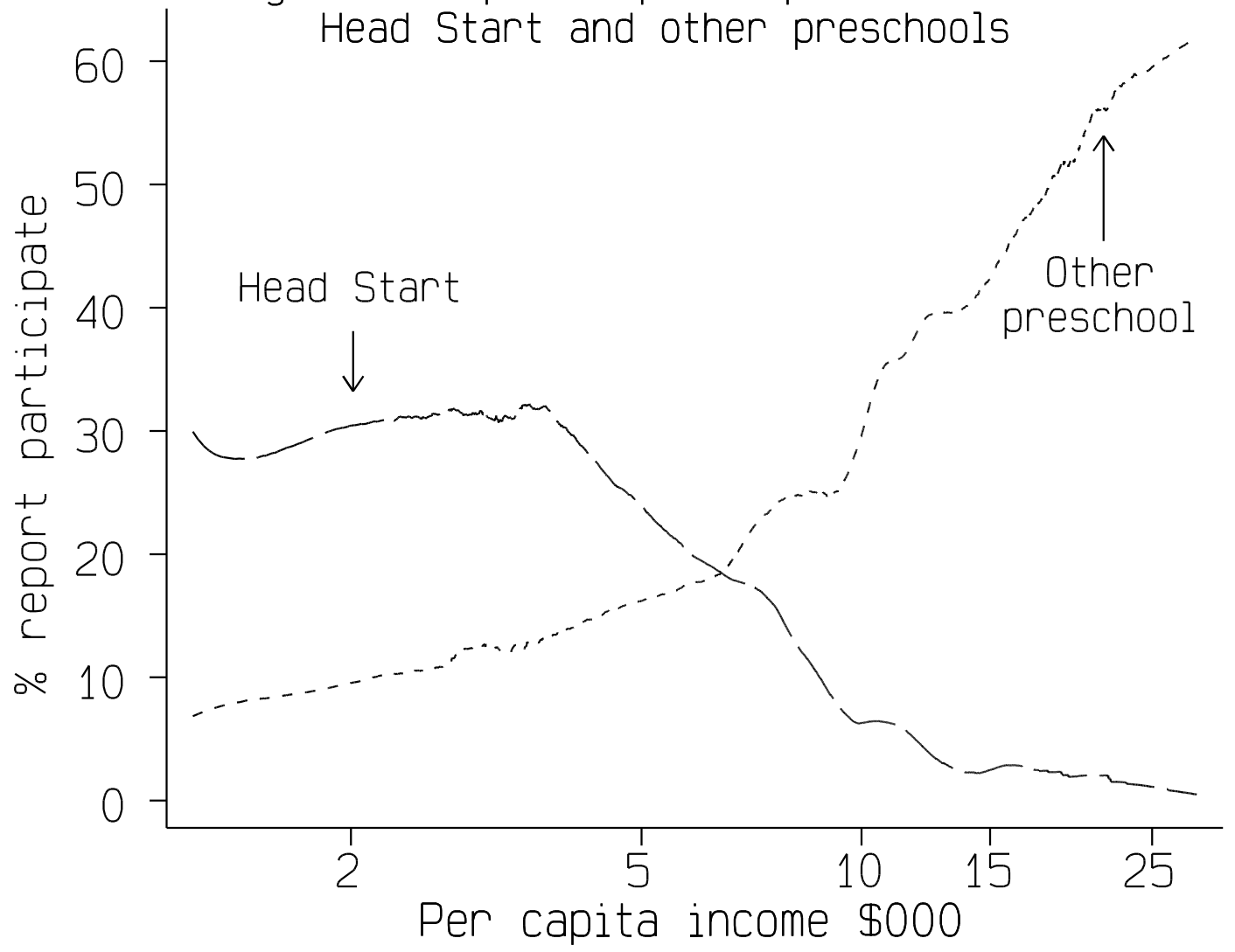


Table 1: Sample summary statistics: Means and [standard errors]

\begin{tabular}{|c|c|c|c|c|}
\hline & $\begin{array}{c}\text { ALL } \\
\text { SAMPLE } \\
\text { (1) }\end{array}$ & $\begin{array}{l}\text { Head } \\
\text { Start } \\
(2)\end{array}$ & $\begin{array}{c}\text { Not in } \\
\text { Head Start } \\
\text { (3) }\end{array}$ & $\begin{array}{l}\text { Sibling } \\
\text { sample } \\
\text { (4) }\end{array}$ \\
\hline \multicolumn{5}{|l|}{$\%$ respondents report participated in } \\
\hline Head Start & $\begin{array}{l}10.57 \\
{[0.53]}\end{array}$ & 100 & 0 & $\begin{array}{l}10.89 \\
{[0.73]}\end{array}$ \\
\hline Other preschool & $\begin{array}{l}28.34 \\
{[0.77]}\end{array}$ & $\begin{array}{l}13.33 \\
{[1.51]}\end{array}$ & $\begin{array}{l}30.11 \\
{[0.85]}\end{array}$ & $\begin{array}{l}27.71 \\
{[1.05]}\end{array}$ \\
\hline \multicolumn{5}{|l|}{ Outcomes } \\
\hline$\%$ completed high school & $\begin{array}{l}76.60 \\
{[0.74]}\end{array}$ & $\begin{array}{l}64.65 \\
{[2.16]}\end{array}$ & $\begin{array}{l}78.03 \\
{[0.79]}\end{array}$ & $\begin{array}{l}77.21 \\
{[1.01]}\end{array}$ \\
\hline$\%$ attended some college & $\begin{array}{l}37.14 \\
{[0.85]}\end{array}$ & $\begin{array}{l}25.08 \\
{[1.96]}\end{array}$ & $\begin{array}{l}38.59 \\
{[0.93]}\end{array}$ & $\begin{array}{l}38.80 \\
{[1.17]}\end{array}$ \\
\hline Earnings (average when resp age 22-24) & 4) 17.29 & 12.10 & 17.81 & 17.31 \\
\hline (\$000 1999 prices) & [0.69] & {$[0.67]$} & {$[0.76]$} & {$[1.00]$} \\
\hline$\%$ charged/convicted of some crime & $\begin{array}{c}9.69 \\
{[0.51]}\end{array}$ & $\begin{array}{l}11.04 \\
{[1.39]}\end{array}$ & $\begin{array}{c}9.53 \\
{[0.54]}\end{array}$ & $\begin{array}{l}10.04 \\
{[0.70]}\end{array}$ \\
\hline \multicolumn{5}{|l|}{ Demographic characteristics } \\
\hline$\%$ African American & $\begin{array}{l}25.17 \\
{[0.74]}\end{array}$ & $\begin{array}{l}75.32 \\
{[1.92]}\end{array}$ & $\begin{array}{l}19.24 \\
{[0.73]}\end{array}$ & $\begin{array}{l}22.85 \\
{[0.98]}\end{array}$ \\
\hline$\%$ female & $\begin{array}{l}51.49 \\
{[0.85]}\end{array}$ & $\begin{array}{l}56.41 \\
{[2.20]}\end{array}$ & $\begin{array}{l}50.91 \\
{[0.93]}\end{array}$ & $\begin{array}{l}50.75 \\
{[1.17]}\end{array}$ \\
\hline Age (years) in 1995 & $\begin{array}{l}23.66 \\
{[0.06]}\end{array}$ & $\begin{array}{l}23.35 \\
{[0.15]}\end{array}$ & $\begin{array}{l}23.70 \\
{[0.06]}\end{array}$ & $\begin{array}{l}23.65 \\
{[0.08]}\end{array}$ \\
\hline$\%$ eldest child in family & $\begin{array}{l}53.11 \\
{[0.56]}\end{array}$ & $\begin{array}{l}50.89 \\
{[1.41]}\end{array}$ & $\begin{array}{l}53.37 \\
{[0.61]}\end{array}$ & $\begin{array}{c}50.57 \\
{[0.76]}\end{array}$ \\
\hline$\%$ low birthweight baby & $\begin{array}{c}6.99 \\
{[0.37]}\end{array}$ & $\begin{array}{l}10.40 \\
{[1.24]}\end{array}$ & $\begin{array}{c}6.59 \\
{[0.38]}\end{array}$ & $\begin{array}{c}6.69 \\
{[0.56]}\end{array}$ \\
\hline \multicolumn{5}{|l|}{ Background } \\
\hline Mother years of education & $\begin{array}{l}12.14 \\
{[0.04]}\end{array}$ & $\begin{array}{l}11.33 \\
{[0.09]}\end{array}$ & $\begin{array}{l}12.24 \\
{[0.04]}\end{array}$ & $\begin{array}{l}12.30 \\
{[0.05]}\end{array}$ \\
\hline$\%$ whose mother completed high school & ol $\begin{array}{c}61.52 \\
{[0.83]}\end{array}$ & $\begin{array}{l}76.39 \\
{[1.89]}\end{array}$ & $\begin{array}{l}59.77 \\
{[0.91]}\end{array}$ & $\begin{array}{l}67.70 \\
{[1.09]}\end{array}$ \\
\hline Father years of education & $\begin{array}{l}11.60 \\
{[0.06]}\end{array}$ & $\begin{array}{l}10.19 \\
{[0.14]}\end{array}$ & $\begin{array}{l}11.76 \\
{[0.06]}\end{array}$ & $\begin{array}{l}12.23 \\
{[0.07]}\end{array}$ \\
\hline$\%$ whose father completed high school & $\begin{array}{l}51.48 \\
{[0.85]}\end{array}$ & $\begin{array}{l}54.59 \\
{[2.21]}\end{array}$ & $\begin{array}{l}51.11 \\
{[0.93]}\end{array}$ & $\begin{array}{l}48.89 \\
{[1.17]}\end{array}$ \\
\hline $\begin{array}{l}\text { Family income (when resp age 3-6) } \\
\quad \text { (\$000 } 1999 \text { prices) }\end{array}$ & $\begin{array}{l}46.23 \\
{[0.46]}\end{array}$ & $\begin{array}{l}26.62 \\
{[0.58]}\end{array}$ & $\begin{array}{l}48.54 \\
{[0.50]}\end{array}$ & $\begin{array}{l}47.33 \\
{[0.67]}\end{array}$ \\
\hline $\begin{array}{l}\% \text { whose mother single } \\
\text { (when resp age } 4 \text { ) }\end{array}$ & $\begin{array}{l}16.42 \\
{[0.61]}\end{array}$ & $\begin{array}{l}40.35 \\
{[2.16]}\end{array}$ & $\begin{array}{l}13.59 \\
{[0.61]}\end{array}$ & $\begin{array}{l}13.06 \\
{[0.79]}\end{array}$ \\
\hline HH size (when resp age 4 ) & $\begin{array}{c}4.59 \\
{[0.03]}\end{array}$ & $\begin{array}{c}4.97 \\
{[0.09]}\end{array}$ & $\begin{array}{c}4.55 \\
{[0.03]}\end{array}$ & $\begin{array}{c}4.84 \\
{[0.04]}\end{array}$ \\
\hline Sample size & 3,255 & 489 & 2,766 & 1,742 \\
\hline
\end{tabular}

Notes: Statistics weighted (so that sample rakes to 1995 Current Population Survey). 


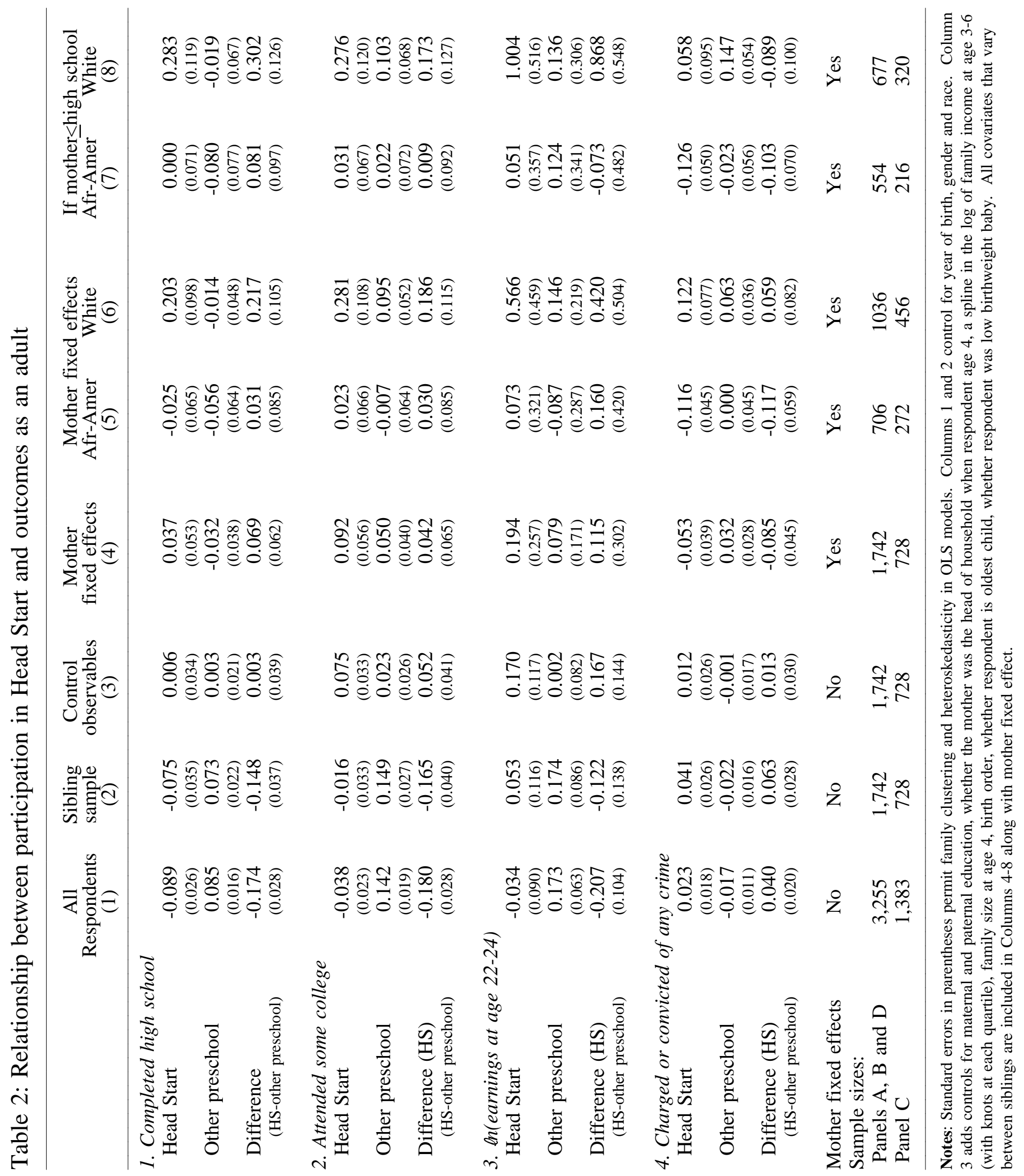


